\title{
An approach based on relations between fuzzy numbers to assess the performance of Tunisian banks
}

\author{
Houssine Tlig ${ }^{\mathrm{a}^{*}}$ and Adel Ben Hamed ${ }^{\mathrm{a}}$
}

${ }^{a}$ Department of Quantitativ Methods, ISG, Gabes University 6029, Tunisia

\begin{tabular}{l}
\hline C H R O N I C L E \\
\hline Article history: \\
Received March 17, 2017 \\
Received in revised format May \\
112017 \\
Accepted May 252017 \\
Available online \\
May 262017 \\
\hline Keywords: \\
Tunisian commercial banks \\
Efficiency \\
FDEA \\
BRONF approach \\
\end{tabular}

A B S T R A C T

This paper aims to evaluate the performance of banks in Tunisia from 2011 to 2013. An approach based on relations between fuzzy numbers (BRONF) is used to solve the fuzzy data envelopment analysis (FDEA) model in presence of financial and non financial data. In addition, a methodology is proposed to treat imprecise inputs and outputs. The results show that, in a competitive environment, no-financial inputs and outputs should be taken into account in order to obtain credible and realistic efficiency scores.

\section{Introduction}

Tunisian commercial banks continue to spend high portion of their budgets on new technologies and innovation in order to enhance their competitiveness. Consequently, performance analysis has become part of their management practices. The decision makers of banks always wish to identify and reduce the underlying causes of inefficiencies and help their firms gain competitive advantage. Traditionally, banks have focused on various profitability ratios to estimate their efficiencies. However, ratio analysis provides relatively insignificant amount of information when we consider the effects of economies of scale, the identification of benchmarking policies, and the estimation of overall performance measures of firms. Another important method used in the evaluation of bank performances is Data Envelopment Analysis (DEA). DEA is a non-parametric method based on linear programming. It provides a relative evaluation of technical efficiency of different firms. This technique can deal with the case of multiple inputs and outputs. Applications of DEA in banking industry are numerous. In these studies, only crisp financial data are used. However, it is not always sufficient to evaluate bank efficiency by taking only

* Corresponding author. Tel.: +21622181437

E-mail address: housni.tlig@gmail.com (H. Tlig) 
financial inputs and outputs as a basis. Nowadays, we see that non-financial performance criteria show up as an emerging asset especially in performance measurement. In general terms, non-financial data are defined as the criteria which cannot be measured with a precise manner and generally given in the form of linguistic terms. These data can be categorized as follows: customer satisfaction, market share, quality-process relation, personnel turnover, quality and flexibility, innovation, supply resources. Fuzzy data envelopment analysis (FDEA) represents an interesting method to deal with this kind of data. This method was applied in some studies to measure the efficiency of banks. Bo et al. (2011) proposed a fuzzy super-efficiency slack-based measure DEA to analyze the performance of 24 commercial banks facing problems on loan and investment parameters with vague characteristics. Kao and Liu (2004) used FCCR model to predict the performance of 24 commercial banks in Taiwan based on their financial forecasts. Wu et al. (2006) used FBCC model to deal with environmental variables in order to assess the efficiency of bank branches from different regions in Canada. Yalcin et al. (2009) developed a multi-criteria decision model to evaluate the performances of Turkish banks. Pramodh et al. (2008) proposed a measurement technique that combines DEA method and Fuzzy Multi Attribute Decision Making technique to measure the productivity levels of Indian banks. Wang et al. (2014) investigated the association between the performance of bank holding companies and their intellectual capital and applied fuzzy multiple objective programming approaches to calculate efficiency scores. Puri and Yadav (2013a) evaluated the fuzzy input mix-efficiency using the $\alpha$-level based approach for the State Bank of Patiala in the Punjab state of India. Puri and Yadav (2013b) proposed another fuzzy DEA model with undesirable fuzzy outputs to calculate the efficiency scores. Chen et al. (2013) applied the Fuzzy Slack-Based Measurement model in the Taiwan banking sector under market risk .

This paper analyses the performance of commercial Tunisian banks in the presence of financial and non-financial inputs and outputs. The BRONF approach proposed by Tlig and Rebai (2009) is applied to obtain the efficiency scores. The remainder of the paper is organised as follow: section 2 gives a brief summary for the evolution of the structure of Tunisian banking sector. Section 3 presents CCR end FCCR models. Section 4 presents the BRONF approach. Section 5 gives the methodology used in this paper. Section 6 gives the empirical results and further discussion. Finally, our conclusions are given in section 7 .

\section{Tunisian banking sector}

Tunisian financial system is dominated by several commercial banks. They not only hold most of the loans deposits, but also they are the major holders of the other financial institutions (insurance companies, leasing companies...). The Tunisian banking sector is composed by 14 commercial banks, 5 development banks, 10 leasing companies, 8 offshore banks and 2 merchant banks. Commercial banks dominate the industry in terms of deposits and loans, they account for $97 \%$ of total assets. In this paper, we focus on commercial banks due to their great importance in this industry. The share of these banks in the credit distribution in 2008 was $85 \%$ compared with $6.7 \%$ for development banks. Commercial banks provide multi product services to satisfy the needs of the Tunisian economy, they are also allowed to collect deposits of any forms and makes short and medium term loans. Since 1986, there was a li-mited movement of new entries the exception was the BH's (Banque de l'Habitat, BH) entry which became the main bank in 1989 specialized in housing credit. This bank represents the third commercial b-ank in terms of total assets. Two other small banks were created: the city bank and the bank of solidarity which remained with limited activity. The absence of new entries are modest over the period 1986-2003, however, deposit banks continued to develop by the extension of their networks, the number of bank branches has increased over the period 1986 -2005 (456 in 1986 compared to 939 in 2005). During the last years the competitive environment has improved, foreign institutions participation in the domestic bank capital structure has increased, and new banking laws has been introduced to reinforce competition. The Tunisian authorities adopted in 2001 the universal bank which gave the development banks approval to compete commercial banks in their activities. This legislation provided a more liberal environment for the exercise of the banking activities. 
The new banking law of 2006 was built to encourage the good governance and recover the credit traditions. This law has some aspects. First, it reinforces banks' governance through internal audit, credit committees and compliance control. Second, it clarifies the conditions of banking activity. Third, it simplifies relationship between customers and their banks. In addition, the BCT has illicit, since 2004, the distribution of dividends by banks that are inadequately provisioned .

The liberalization program of the Tunisian banking sector aims at the emergence of a new banking landscape. First, deregulation targeted interest rates, allowing banks to make freely credit decisions. The money market average rate encouraged banks to fix their rates. In 1994, the equity market was restructured and aims to improve its liquidity. In 1996, the rediscount refinancing technique was replaced by the market open technique. In addition, government financing moved gradually to be market-based and banks were less and less concerned by holding treasury bills.

\section{DEA and FDEA models}

The basic DEA models are the CCR model proposed by Charnes et al. (1978) and the model of Banker et al. (1984) called the BCC model. The two models differ in the way they treat returns to scale. The CCR model assumes constant return to scale. The BCC model is more flexible and allows variable returns to scale. Other DEA models exist and all are extensions of the CCR model. Consider $N$ decision making units $\left(D M U_{s}\right)$, each uses $m$ inputs $\left(x_{1}, \ldots, x_{m}\right)$ to produce $s$ different outputs $\left(y_{1}, \ldots, y_{s}\right)$. The programming statement for the CCR primal model (input oriented) and its dual is given as follow:

$$
\begin{array}{ll}
\min & \theta_{0} \\
\text { s.t. } & \sum_{j=1}^{n} \lambda_{j} x_{i j} \leq \theta_{0} x_{i 0}, \quad i=1, \ldots ., m, \\
& \sum_{j=1}^{n} \lambda_{j} y_{r j} \geq y_{r 0}, \quad r=1, \ldots ., s, \\
& \lambda_{j} \geq 0, \quad j=1, \ldots ., N .
\end{array}
$$

In this model, $u_{i}$ represents the weight of the ith input and $v_{r}$ is the weight of the rth output. The target decision maker unit (DMU) is technically efficient if and only if the value of $\theta$ at the optimality is equal to 1 and so it's not possible to make improvement without worsening any other input or output. The dual form of model (1) is given by

$$
\begin{array}{ll}
\max & \sum_{r=1}^{s} v_{r} y_{r 0}, \quad r=1, \ldots ., s, \\
\text { s.t. } & \sum_{i=1}^{m} u_{i} x_{i 0}=1, i=1, \ldots ., m, \\
& \sum_{i=1}^{m} u_{i} x_{i j} \geq \sum_{r=1}^{s} v_{r} y_{r j}, j=1, \ldots ., N, \\
& u_{i}, v_{r} \geq 0 .
\end{array}
$$

When fuzzy inputs and fuzzy outputs exist in the performance evaluation process, model (2) becomes:

$$
\begin{aligned}
\max & \sum_{r=1}^{s} v_{r} \tilde{y}_{r 0}, \quad r=1, \ldots ., s, \\
\text { s.t. } & \sum_{i=1}^{m} u_{i} \tilde{x}_{i 0}=1, \quad i=1, \ldots, m, \\
& \sum_{i=1}^{m} u_{i} \tilde{x}_{i j} \geq \sum_{r=1}^{s} v_{r} \tilde{y}_{r j}, \quad j=1, \ldots, n, \\
& u_{i} \geq 0, \quad v_{i} \geq 0,
\end{aligned}
$$

where $\tilde{x}_{i j}$ and $\tilde{y}_{r j}$ are respectively the ith fuzzy input and the rth fuzzy output. 
The FCCR model (3) takes the form of fuzzy linear programming problems. Fuzzy set theory is used as alternative to treat the imprecision and the vagueness in DEA models. The interpretation of constraints of FCCR model is similar to the crisp CCR model. The difference between the two models resides on the manner of resolution. The crisp CCR model can be simply solved by a standard LP solver. For the FCCR model, the resolution is more difficult and requires some ranking methods of fuzzy sets. These methods are usually categorised into four approaches. The first is the tolerance approach developed by Sengupta (1992) and further improved by Kahraman and Tolga (1998). The main idea of this approach consists to incorporate uncertainty into DEA models by specifying tolerance levels on constraint violations. This approach fuzzifies the inequality or equality signs but it does not treat fuzzy coefficients directly. The limitation of the tolerance approach appears in the case of DEA models with a fuzzy objective function and fuzzy constraints which may or may not be satisfied (Triantis, 1998). Although in most production processes fuzziness is present both in terms of not meeting specific objectives and in terms of the imprecision of the data, the tolerance approach provides flexibility by relaxing the DEA relationships while the input and output coefficients are treated as crisp. The $\alpha$-level approach is frequently used approach to treat the imprecision in FDEA models. The main idea consists to convert the fuzzy DEA model into a pair of parametric programs in order to find the lower and upper bounds at an $\alpha$-level of the membership functions of the efficiency scores. Kao and Liu (2000) used this approach to transform the fuzzy DEA model to a family of conventional crisp DEA models and developed a solution procedure to measure the efficiencies of the DMUs with fuzzy observations in the BCC model. Their method found approximately the membership functions of the fuzzy efficiency obtained by the application of the $\alpha$-level approach and Zadeh's extension principle (Zadeh, 1978) Saati et al. (2002) suggested a fuzzy CCR model as a possibilistic programming problem and transformed it into an interval programming problem using $\alpha$-level based approach. The resulting interval programming problem could be solved as a crisp LP model for a given $\alpha$ with some variable substitutions. Saati and Memariani (2005) proposed a technique for finding a common set of weights in fuzzy DEA based on the $\alpha$-level approach with triangular fuzzy data. Liu (2008) suggested a fuzzy DEA procedure to obtain the efficiency measures embedded with assurance region (AR) concept when some observations were triangular fuzzy numbers. He combined the $\alpha$-level approach and the extension principle to transform the fuzzy DEA/AR model into a pair of parametric mathematical programs and worked out the lower and upper bounds of the efficiency scores of the DMUs. Wang et al. (2009) developed a fuzzy DEA-Neural approach with a self-organizing map for classification in their neural network. The fuzzy ranking approach is also another popular technique that has attracted a great deal of attention in the fuzzy DEA literature. In this approach the main idea is to obtain the fuzzy efficiency scores of the DMUs using fuzzy linear programs which require ranking fuzzy sets. The fuzzy ranking approach was initially developed by Guo and Tanaka (2001) Tlig and Rebai (2009) proposed an approach based on the ordering relations between LR-fuzzy numbers to solve the primal and the dual of FCCR. They suggested a procedure based on the resolution of a goal programming problem to transform the fuzzy normalisation equality in the primal of FCCR. Another popular approach is the possibility approach. Guo et al. (2000) initially built fuzzy DEA models based on possibility and necessity measures and then Lertworasirikul (2002) and Lertworasirikul et al. (2003) have proposed two methods for solving the ranking problem in fuzzy DEA models called the "possibility models" and the "credibility models." They used the possibility approach from both optimistic and pessimistic view points by considering the uncertainty in fuzzy objectives and fuzzy constraints with possibility measures. In their credibility approach, fuzzy DEA model was transformed into a credibility programming-DEA model and fuzzy variables were replaced by "expected credits," which were obtained by using credibility measures.

\section{The BRONF approach}

Suppose that the fuzzy inputs and outputs in the FCCR model are represented by $L R$-fuzzy numbers and let:

$\tilde{x}_{i j}=\left(x_{l i j}, x_{u i j}, a_{i j}, b_{i j}\right)_{R R}:$ The input i consumed by DMUj,

$\tilde{y}_{r j}=\left(y_{l r j}, y_{u r j} c_{r j}, d_{r j}\right)_{L^{\prime} R^{\prime}}$ : The output $\mathrm{r}$ consumed by DMUj,

$L_{i j}^{-1}(h)$ : The inverse of the left reference function of $\tilde{x}_{i j}$.

$R_{i j}^{-1}(h)$ : The inverse of the right reference function of $\tilde{x}_{i j}$.

$L_{r j}^{-1}(h)$ : The inverse of the left reference function of $\tilde{y}_{r j}$.

$R_{r j}^{\prime-1}(h)$ : The inverse of the right reference function of $\tilde{y}_{r j}$. 
The BRONF approach consists to use the ordering relations between fuzzy numbers and the goal programming to solve FDEA models. We used this approach to solve the primal of FCCR. First, let us consider the objective function $\max \sum_{r=1}^{s} v_{r} \tilde{y}_{r 0}$. Because of the efficiency value is positive; the objective function can be regarded as a constraint ( $\left.\max \sum_{r=1}^{s} v_{r} \tilde{y}_{r 0} \geq 0\right)$. Using the ordering relation between fuzzy numbers, this constraint can be converted into two crisp relations as follow:

$\max \sum_{r=1}^{s} v_{r}\left(y_{l r 0}-c_{r 0} L_{r 0}^{\prime}{ }^{-1}(h)\right), \quad h \in[0,1], \quad$ and, $\max \sum_{r=1}^{s} v_{r}\left(y_{u r 0}+d_{r 0} R_{r 0}^{\prime-1}(h)\right), \quad h \in[0,1]$. then, $\max \sum_{r=1}^{s} v_{r} \tilde{y}_{r 0}$ is equivalent to maximise $\sum_{r=1}^{s} v_{r}\left(y_{l r 0}-c_{r 0} L_{r 0}^{\prime-1}(h)\right)$ and $\sum_{r=1}^{s} v_{r}\left(y_{u r 0}+d_{r 0} R_{r 0}^{\prime-1}(h)\right)$ simultaneously. A weighted function $\lambda_{1} \sum_{r=1}^{s} v_{r}\left(y_{l r 0}-c_{r 0} L_{r 0}^{r=1}-1(h)\right)+\lambda_{2} \sum_{r=1}^{s} v_{r}\left(y_{u r 0}+d_{r 0} R_{r 0}^{r=1}(h)\right)$, with $\lambda_{1} \geq 0, \lambda_{2} \geq 0$ and $\lambda_{1}+\lambda_{2}=1$ is used to obtain some compromise solution. Here, the values of $\lambda_{1}$ and $\lambda_{2}$ reflect the opinion of the decision maker, we consider three cases; optimistic if $\lambda_{2}=1$, pessimistic if $\lambda_{1}=1$ and indifferent if $\lambda_{1}=\lambda_{2}$. Then the following objective function is obtained:

$$
\max \lambda_{1} \sum_{r=1}^{s} v_{r}\left(y_{l r 0}-c_{r 0} L_{r 0}^{\prime-1}(h)\right)+\lambda_{2} \sum_{r=1}^{s} v_{r}\left(y_{u r 0}+d_{r 0} R_{r 0}^{\prime-1}(h)\right)
$$

Next, let us consider the normalisation equality $\sum_{i=1}^{m} u_{i} \tilde{x}_{i 0}=1$. We transform this relation into two crisp equalities as follow:

$$
\begin{aligned}
& \sum_{i=1}^{m} u_{i}\left(x_{l i j}-a_{i j} L_{i j}^{-1}(h)\right)=1, \\
& \sum_{i=1}^{m} u_{i}\left(x_{u i j}+a_{i j} R_{i j}^{-1}(h)\right)=1 .
\end{aligned}
$$

Here, weights $u_{i}$ cannot be found out to satisfy Eq. (5) simultaneously. To avoid this difficulty, we consider each equality as a goal to achieve. Thus, a goal programming problem must be constructed:

$$
\begin{array}{ll}
\text { Min } & d_{1}^{+}+d_{1}^{-}+d_{2}^{+}+d_{2}^{-} \\
\text {s.t. } & \sum_{i=1}^{m} u_{i}\left(x_{l i j}-a_{i j} L_{i j}^{-1}(h)\right)-d_{1}^{+}+d_{1}^{-}=1, \quad i=1, \ldots ., m, \\
& \sum_{i=1}^{m} u_{i}\left(x_{u i j}+a_{i j} R_{i j}^{-1}(h)\right)-d_{2}^{+}+d_{2}^{-}=1, \quad i=1, \ldots, m . \\
& d_{1}^{+}, d_{2}^{+}, d_{1}^{-}, d_{2}^{-} \geq 0 \\
& u_{i} \geq 0, \quad h \in[0,1], \quad j=1, \ldots ., n
\end{array}
$$

where $d_{i}^{+}$et $d_{i}^{-}$are respectively the negative and positive deviation corresponding to goal $g_{j}, j=\{1,2\}$. Solving problem (6) provides the values of $\rho_{i}\left(\rho_{i}=d_{i}^{+}-d_{i}^{-}\right)$. These values are added to the left sides of Eq. (5) and finally the equality $\sum_{i=1}^{m} u_{i} \tilde{x}_{i 0}=1$ is converted as follow:

$$
\begin{aligned}
& \sum_{i=1}^{m} u_{i}\left(x_{l i j}-a_{i j} L_{i j}^{-1}(h)\right)-\rho_{1}=1, \\
& \sum_{i=1}^{m} u_{i}\left(x_{u i j}+a_{i j} R_{i j}^{-1}(h)\right)-\rho_{2}=1 .
\end{aligned}
$$

The use of ordering relation, at a given possibility level $h$, allows us to transform the constraint $\sum_{i=1}^{m} u_{i} \tilde{x}_{i j} \geq \sum_{r=1}^{s} v_{r} \tilde{y}_{r j}$ into two the following crisp relations 
$\sum_{i=1}^{m} u_{i}\left(x_{l i j}-a_{i j} L_{i j}^{-1}(h)\right) \geq \sum_{r=1}^{s} v_{r}\left(y_{l r j}-c_{r j} L_{r j}^{\prime-}(h)\right)$,

and $\sum_{i=1}^{m} u_{i}\left(x_{u i j}+b_{i j} R_{i j}^{-1}(h)\right) \geq \sum_{r=1}^{s} v_{r}\left(y_{u r j}+d_{r j} R_{r j}^{\prime-1}(h)\right)$.

Finally, the primal of fuzzy CCR can be transformed into the following crisp linear problem:

$$
\begin{aligned}
\max & \lambda_{1} \sum_{r=1}^{s} v_{r}\left(y_{l r 0}-c_{r 0} L_{r 0}^{\prime-1}(h)\right)+\lambda_{2} \sum_{r=1}^{s} v_{r}\left(y_{u r 0}+d_{r 0} R_{r 0}^{\prime-1}(h)\right) \\
& \sum_{i=1}^{m} u_{i}\left(x_{l i j}-a_{i j} L_{i j}^{-1}(h)\right)-\rho_{1}=1, \\
& \sum_{i=1}^{m} u_{i}\left(x_{u i j}+a_{i j} R_{i j}^{-1}(h)\right)-\rho_{2}=1 . \\
& \sum_{i=1}^{m} u_{i}\left(x_{l i j}-a_{i j} L_{i j}^{-1}(h)\right) \geq \sum_{r=1}^{s} v_{r}\left(y_{l r j}-c_{r j} L_{r j}^{-}(h)\right), \\
& \sum_{i=1}^{m} u_{i}\left(x_{u i j}+b_{i j} R_{i j}^{-1}(h)\right) \geq \sum_{r=1}^{s} v_{r}\left(y_{l r j}+d_{r j} R_{r j}^{\prime-1}(h)\right) \\
& u_{i} \geq 0, \quad v_{r} \geq 0, \quad h \in[0,1]
\end{aligned}
$$

When the inputs and the outputs are given by triangular fuzzy numbers, model (9) is as follows,

$$
\begin{array}{ll}
\max & \lambda_{1} \sum_{r=1}^{s} v_{r}\left(y_{r 0}-c_{r 0}(1-h)\right)+\lambda_{2} \sum_{r=1}^{s} v_{r}\left(y_{r 0}+d_{r 0}(1-h)\right), \\
\text { s.t. } \quad & \sum_{i=1}^{m} u_{i}\left(x_{i 0}-a_{i 0}(1-h)\right)-\rho_{1}=1, \\
& \sum_{i=1}^{m} u_{i}\left(x_{i 0}+a_{i 0}(1-h)\right)-\rho_{2}=1, \\
& \sum_{i=1}^{m} u_{i}\left(x_{i j}-a_{i j}(1-h)\right) \geq \sum_{r=1}^{s} v_{r}\left(y_{r j}-c_{r j}(1-h)\right) \\
& \sum_{i=1}^{m} u_{i}\left(x_{i j}+b_{i j}(1-h)\right) \geq \sum_{r=1}^{s} v_{r}\left(y_{r j}+d_{r j}(1-h)\right) \\
& u \geq 0, v \geq 0, h \in[0,1]
\end{array}
$$

\section{Methodology}

In this paper, our study aims to evaluate the efficiency scores of 14 commercial Tunisian banks in terms of crisp and imprecise data during the period 2011-2013. We focus on the intermediary approach.

Three crisp inputs (deposits, labour and fixed assets) and two crisp outputs (loans and portfolio investment) have been used. The source of these data is the PATB (Professional association of Tunisian Banks). The fixed assets, deposits, loans and portfolio investment are measured in TND and labour is measured in terms of number of staff. Imprecise used data are the innovation level as input and customer's satisfaction as output. These data were obtained from two questionnaires. The first questionnaire is addressed to 120 potential customers of each bank. Every respondent gave a note in the interval $[0,20]$ that reflects his degree of satisfaction (Not at all satisfied, unsatisfied, moderately satisfied, "satisfied, and very satisfied). From these notes, a triangular fuzzy number $\tilde{y}=\left(y_{l}, y, y_{u}\right)$ is assigned to each bank, where $y_{l}$ and $y_{u}$ are respectively the lower and the upper note given by the respondents and $y$ is the midpoint of $\left[y_{l}, y_{u}\right]$.The left spread and the right spread are given by $c=y-y_{l}$ and $d=y_{u}-y$, respectively. Table 1 gives the customer's satisfaction data for each bank. 
Table 1

The customer's satisfaction data

\begin{tabular}{|c|c|c|c|}
\hline Bank & 2011 & 2012 & 2013 \\
\hline BNA & $(11,13.5,16)$ & $(10,12.5,15)$ & $(12,13,14)$ \\
\hline STB & $(10,11,12)$ & $(11,12,13)$ & $(11,13.5,16)$ \\
\hline BIAT & $(11,13,15)$ & $(10,13,16)$ & $(11,11.5,12)$ \\
\hline UIB & $(9,10.5,12)$ & $(10,11,12)$ & $(12,13.5,15)$ \\
\hline $\mathrm{BH}$ & $(11,12,13)$ & $(9,10.5,12)$ & $(9,10.5,12)$ \\
\hline BS & $(10,13,16)$ & $(11,12.5,16)$ & $(10,12.5,15)$ \\
\hline BT & $(9,10.5,12)$ & $(9,11.5,14)$ & $(11,11.5,12)$ \\
\hline UBCI & $(8,10,12)$ & $(9,9.5,10)$ & $(9,10,11)$ \\
\hline ATB & $(10,12.5,15)$ & $(10,12.5,15)$ & $(9,11,13)$ \\
\hline $\mathrm{AB}$ & $(11,13.5,16)$ & $(10,12.5,15)$ & $(10,12.5,15)$ \\
\hline BFT & $(6,8.5,11)$ & $(6,8,10)$ & $(7,8,9)$ \\
\hline $\mathrm{CB}$ & $(9,11.5,14)$ & $(8,10,12)$ & $(8,10,12)$ \\
\hline BTS & $(8,11,14)$ & $(8,10,12)$ & $(6,8,10)$ \\
\hline $\mathrm{ABCT}$ & $(5,7,9)$ & $(6,7,8)$ & $(8,10,12)$ \\
\hline
\end{tabular}

The second questionnaire was addressed to 60 technical person of each bank. Every respondent describes his judgment about the innovation degree in his bank by linguistic terms (very low, low, high and very high) and gave a score of innovation level in the interval $[0,20]$. From these scores, a triangular fuzzy number $\tilde{x}=\left(x_{l}, x, x_{u}\right)$, where $x_{l}$ and $x_{u}$ are respectively the lower and the upper note given by the respondents and $x$ is the midpoint of $\left[x_{l}, x_{u}\right]$.The left spread and the right spread are given by $a=x-x_{l}$ and $b=x_{u}-x$, respectively. Table 2 gives results of the innovation level data for each bank.

Table 2

The results of the innovation level data

\begin{tabular}{cccc}
\hline bank & 2011 & 2012 & 2013 \\
\hline BNA & $(14,15,16)$ & $(12,12.5,13)$ & $(12,13,14)$ \\
STB & $(12,13,14)$ & $(11,12,13)$ & $(11,13.5,16)$ \\
BIAT & $(12,13,14)$ & $(11,13.5,16)$ & $(12,13.5,15)$ \\
UIB & $(9,10.5,12)$ & $(11,11.5,12)$ & $(12,13.5,15)$ \\
BH & $(12,14,16)$ & $(12,14,16)$ & $(10,12.5,15)$ \\
BS & $(12,14,16)$ & $(11,12.5,16)$ & $(11,11.5,12)$ \\
BT & $(12,13,14)$ & $(10,12,14)$ & $(12,12.5,13)$ \\
UBCI & $(10,11,12)$ & $(11,10.5,12)$ & $(11,12,14)$ \\
ATB & $(13,14,15)$ & $(12,12.5,16)$ \\
AB & $(12,14,16)$ & $(11,12,14)$ & $(8,10,12)$ \\
BFT & $(12,13,14)$ & $(10,11,12)$ & $(10,10.5,11)$ \\
CB & $(10,12,14)$ & $(8,10,12)$ & $(10,12,14)$ \\
BTS & $(10,12,14)$ & $(10,10.5,11)$ & $(10,10.5,11)$ \\
\hline
\end{tabular}

\section{The results}

The results indicate that large banks (STB, BIAT and BNA) are more efficient than small banks (BFT, $\mathrm{BC}, \ldots)$ and medium-sized banks(BT,BH, $\mathrm{AB})$. This superiority efficiency score can be explained by better resource management and better organization. In addition, these banks make big part of their capital in new technologies and diversified their marketing strategies in order to satisfy their customers.

As seen in Table 3, in 2011, the mean efficiency score obtained by the BRONF approach was 0,879 at the possibility level 0.25 . This means that Tunisian banks could reduce their level of inputs by $12.1 \%$ to become efficient. The efficient frontier is constructed by the large banks (BNA. STB and BIAT) which are public banks. The medium-sized banks, especially the UIB and BT are inefficient, but they are not far from the frontier. Indeed, they have a mean efficiency score above 0.790 for all possibility levels. In 2011, the mean efficiency scores vary between $84.6 \%$ and $89,1 \%$. The highest scores are obtained in 2013 and the lowest are registered in 2011, which is the year of Tunisian revolution. 
Table 3

Efficiency scores obtained by the BRONF approach

\begin{tabular}{|c|c|c|c|c|c|c|c|c|}
\hline Year & $\mathrm{h}$ & BNA & STB & BIAT & UIB & $\mathrm{BH}$ & BS & BT \\
\hline \multirow{5}{*}{2011} & 0 & 1 & 1 & 1 & 0.878 & 0.797 & 0.799 & 0.785 \\
\hline & 0.25 & 1 & 1 & 1 & 0,871 & 0,774 & 0,791 & 0,723 \\
\hline & 0.5 & 1 & 1 & 1 & 0.863 & 0.763 & 0.796 & 0,723 \\
\hline & 0.75 & 1 & 1 & 1 & 0.854 & 0.762 & 0.786 & 0,722 \\
\hline & 1 & 1 & 1 & 1 & 0.846 & 0.76 & 0.785 & 0,721 \\
\hline \multirow{5}{*}{2012} & 0 & 1 & 1 & 1 & 0.879 & 0.801 & 0.799 & 0.786 \\
\hline & 0.25 & 1 & 1 & 1 & 0,873 & 0,794 & 0,798 & 0,753 \\
\hline & 0.5 & 1 & 1 & 1 & 0.869 & 0.783 & 0.797 & 0,749 \\
\hline & 0.75 & 1 & 1 & 1 & 0.858 & 0.765 & 0.789 & 0,732 \\
\hline & 1 & 1 & 1 & 1 & 0.849 & 0.764 & 0.788 & 0,731 \\
\hline \multirow{5}{*}{2013} & 0 & 1 & 1 & 1 & 0.903 & 0.852 & 0.813 & 0.789 \\
\hline & 0.25 & 1 & 1 & 1 & 0,893 & 0,849 & 0,812 & 0,786 \\
\hline & 0.5 & 1 & 1 & 1 & 0.896 & 0.833 & 0.799 & 0,779 \\
\hline & 0.75 & 1 & 1 & 1 & 0.888 & 0.833 & 0.787 & 0,773 \\
\hline & 1 & 1 & 1 & 1 & 0.886 & 0.83 & 0.786 & 0,771 \\
\hline Year & $\mathrm{h}$ & UBCI & ATB & A.B & BFT & C.B & BTS & ABCT \\
\hline \multirow{5}{*}{2011} & 0 & 0.712 & 0.842 & 0.799 & 0.899 & 0.837 & 0.808 & 0.868 \\
\hline & 0.25 & 0,710 & 0,740 & 0,796 & 0,793 & 0,737 & 0,707 & 0,759 \\
\hline & 0.5 & 0.708 & 0.738 & 0.794 & 0.783 & 0.735 & 0.706 & 0.753 \\
\hline & 0.75 & 0.707 & 0.736 & 0.793 & 0.782 & 0.731 & 0.706 & 0.75 \\
\hline & 1 & 0.705 & 0.733 & 0.79 & 0.78 & 0.729 & 0.705 & 0.748 \\
\hline \multirow{5}{*}{2012} & 0 & 0.728 & 0.843 & 0.81 & 0.811 & 0.847 & 0.818 & 0.868 \\
\hline & 0.25 & 0,719 & 0,742 & 0,799 & 0,810 & 0,747 & 0,797 & 0,799 \\
\hline & 0.5 & 0.718 & 0.739 & 0.794 & 0.803 & 0.746 & 0.796 & 0.783 \\
\hline & 0.75 & 0.707 & 0.738 & 0.794 & 0.802 & 0.738 & 0.796 & 0.78 \\
\hline & 1 & 0.706 & 0.736 & 0.793 & 0.8 & 0.729 & 0.795 & 0.778 \\
\hline \multirow{5}{*}{2013} & 0 & 0.729 & 0.844 & 0.814 & 0.819 & 0.867 & 0.821 & 0.879 \\
\hline & 0.25 & 0,729 & 0,743 & 0,811 & 0,818 & 0,799 & 0,813 & 0,801 \\
\hline & 0.5 & 0.728 & 0.739 & 0.797 & 0.813 & 0.796 & 0.799 & 0.793 \\
\hline & 0.75 & 0.717 & 0.739 & 0.796 & 0.809 & 0.789 & 0.797 & 0.789 \\
\hline & 1 & 0.716 & 0.737 & 0.793 & 0.805 & 0.777 & 0.797 & 0.788 \\
\hline
\end{tabular}




\section{Conclusion}

The banking sector is of great importance to Tunisian's economy. Major commercial banks continue to spend high proportion of their budgets on new technologies and innovation in order to satisfy their customers and enhance their competitiveness. Consequently, performance analysis has become part of their management practices. In this study, we propose an empirical study that consists to assessing the performance of commercial banks in Tunisia during the period 2011-2013. The empirical results show that large banks are the most efficient because they spend much of their total budget for investment in new technologies.

\section{References}

Banker, R.D., Charnes, A. and Cooper, W.W. (1984) Some models for estimating technical and scale inefficiencies in data envelopment analysis, Management Science,30, 1078-1092.

BO, H., Ching, and Ching, R.C. (2011) Using fuzzy super efficiency slack-based measure data envelopment analysis to evaluate Taiwan's commercial bank efficiency, Expert Systems with Applications, 38 , 9147-9156.

Charnes, A., Cooper, W.W and Rhodes, E. (1978) Measuring the efficiency of decision making units, European Journal of Operations Research , 4, 29-44.

Chen, Y.C., Chiu, Y.H., Huang, C.W. and Tu, C.H. (2013) The analysis of bank business performance and market risk-Applying Fuzzy DEA, Economic Modeling, 32, 225-232.

Guo, P. And Tanaka, H. (2001) Fuzzy DEA: a perceptual evaluation method, Fuzzy Sets and Systems, 119, 149-160.

Guo, P., Tanaka, H. and Inuiguchi, M. (2000) Self-organizing fuzzy aggregation models to rank the objects with multiple attributes, IEEE Transactions on Systems, Man and Cybernetics, Part ASystems and Humans, 30, 573-580.

Kahraman, C. And Tolga, E. (1988) Data envelopment analysis using fuzzy concept, 28th International Symposium on Multiple-Valued Logic, 338-343.

Kao, C. And Liu, S.T. (2000) Fuzzy efficiency measures in data envelopment analysis, Fuzzy Sets and Systems, 113, 427-437.

Kao, C., and Liu, S.T. (2004) Predicting bank performance with financial forecasts: A case of Taiwan commercial banks, Journal of Banking \& Finance, 28, 2353-2368.

Lertworasirikul, S. (2002) Fuzzy Data Envelopment Analysis (DEA), Ph.D. Dissertation, Department of Industrial Engineering, North Carolina State University.

Lertworasirikul, S., Fang, S.C., Joines, J.A. and H. L.W. Nuttle, H.L.W. (2003) Fuzzy data envelopment analysis (DEA): a possibility approach, Fuzzy Sets and Systems, 139, 379-394.

Liu, S.T. (2008) A fuzzy DEA/AR approach to the selection of flexible manufacturing system. Computer and Industrial Engineering, 54, 66-76.

Pramodh, C., Ravi, V. and Hushanam, N. (2008) Indian banks' productivity ranking via Data Envelopment Analysis and Fuzzy Multi-Attribute Decision-Making hybrid, International Journal of Information and Decision Science, 1, 44-65.

Puri, J.and Yadav, S.P. (2013) A concept of fuzzy input mix-efficiency in fuzzy DEA and its application in banking sector, Expert Systems with Applications, 40 (5), 1437-1450.

Puri, J.and Yadav, S.P. (2013), A fuzzy DEA model with undesirable fuzzy outputs and its application to the banking sector in India, Expert Systems with Applications, 41(14) , 6419-6432.

Saati, S. And Memariani, A. (2005) Reducing weight flexibility in fuzzy DEA, Applied Mathematics and Computation, 161, 611-622.

Saati, S., Memariani, A. And ahanshahloo, G.R. (2002) Efficiency analysis and ranking of DMUs with fuzzy data, Fuzzy Optimization and Decision Making, 1, 255-267.

Sengupta, J.K. (1992) A fuzzy systems approach in data envelopment analysis, Computers and Mathematics with Applications, 24 259-266.

Tlig, H. And Rebai, A. (2009) mathematical approach to solve data envelopment analysis models when data are LR fuzzy numbers, Applied Mathematical Sciences, 3, 2383-2396.

Triantis, K.P., Girod, O. (1998) A mathematical programming approach for measuring technical efficiency in a fuzzy environment, Journal of Productivity Analysis, 10, 85-102.

Wang, C.H., Chuang, C.C. and Tsai, C.C. (2009) A fuzzy DEA-neural approach to measuring design service performance in PCM projects, Automation in Construction, 18, 702-713. 
Wang, W.K , Lu, W.M and Liu, P.L. (2014) A fuzzy multi-objective two-stage DEA model for evaluating the performance of US bank holding companies, Expert Systems with Applications, 41(9) , 4290-4297.

$\mathrm{Wu}, \mathrm{D} . \mathrm{D}$, Yang, Z. and Liang, L. (2006), Efficiency analysis of cross-region bank branches using fuzzy data envelopment analysis, Applied Mathematics and Computation, 181, 271-281.

Yalcin, N.S., Ali, B. and Kahraman, C. (2009) Fuzzy performance evaluation in Turkish Banking Sector using Analytic Hierarchy Process and TOPSIS, Expert Systems with Applications 36, 1169911709.

Zadeh, L.A. (1978) Fuzzy sets as a basis for a theory of possibility, Fuzzy Sets and Systems, 1, 3-28.

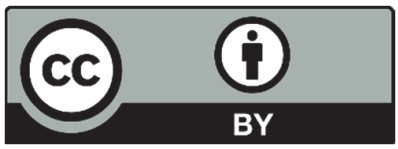

(C) 2018 by the authors; licensee Growing Science, Canada. This is an open access article distributed under the terms and conditions of the Creative Commons Attribution (CC-BY) license (http://creativecommons.org/licenses/by/4.0/). 